\title{
Research and Practices of Scientific Research Services of Local Higher Vocational Colleges
}

\author{
Jing LV \\ Xi'an Aeronautical Polytechnic Institute Office of Academic Research, Xi'an 710089, China. \\ xihang710089@163.com
}

Keywords: higher vocational college; scientific research service; scientific research project.

\begin{abstract}
Based on the incentive and service systems of scientific research at local higher vocational colleges, duties and missions of college leaders, tier-two school leaders, directors of scientific research projects, individual scientific researchers and the management departments on scientific research in colleges involved in scientific research activities were analyzed. A scientific research management idea was proposed, taking scientific research services as the main body, development demands of key disciplines as the basis, and applications for scientific research projects as the guidance, and aimed to enhance scientific research service strength and create good scientific research conditions, therefore to upgrade the teaching quality of higher vocational colleges under two-tier college system, reinforce their ability to serve local society, and boost connotation construction. Colleges mainly function in three ways, namely cultivating talents, scientific research, and serving the society. Scientific research, in particular, is a major function of colleges as well as an important channel through which talents are cultivated. With the ongoing development of knowledge economy in China and increasing demand for highly-skilled talents, the scientific research workload of higher vocational colleges in cultivating highly-skilled applied talents increases steeply, and many colleges begin to adopt a two-tier model to manage the scientific research affairs at college and school level. As a major part in the connotation construction of higher vocational colleges, scientific research represents the development degree of connotation in such colleges, and more importantly, is the basis and a key factor in cultivating talents, performing scientific research, and serving the society.
\end{abstract}

\section{Introduction}

It's stressed in Upgrade Quality - Guidelines on Pedagogical Practices and Scientific Research Management for Higher Vocational Colleges (Joint Conference of National Higher Vocational College Headmasters held by Department of Higher Education, Ministry of Education of The People's Republic of China) that "scientific research plays a vital role in higher vocational colleges. Pedagogical practices and scientific research of higher education are interiorly connected. Not only is scientific research the main way in which colleges serve the society, but also a key means of cultivating talents, improving faculty quality, and promoting the development of disciplines. Pedagogical practices can further extend the scientific achievements of teachers and scientific research can in return promote teaching quality, while the basic theories teachers master in pedagogical practices and students' active minds can further promote scientific research, which reveals the tight relationship between pedagogical practice and scientific research" [1]. To thoroughly improve teaching quality of higher vocational colleges, not only teaching tasks shall be well performed, but also close attention shall be paid to scientific research and the management thereof. And, to accomplish scientific and standard management of scientific research at higher vocational colleges, duties of involved parts shall be analyzed in accordance to the real needs of colleges, under the two-tier management model, and in combination with characteristics of higher vocational education, so as to reach the goal of enhancing scientific research management and creating scientific research conditions, and therefore to upgrade teaching quality, enhance colleges' ability to serve local society, and develop connotation construction. 


\section{Strategy and Responsibility for Scientific Research for University (School) Leaders to Understand}

\subsection{Scientific Research Strategies that College (School) Leaders Should Know.}

To smoothly perform scientific research at higher vocational colleges adopting the two-tier management model, college leaders shall above all be aware of the importance of scientific research and its development strategies. Considering the weak awareness of the importance of scientific research at higher vocational colleges in comparison with at universities, the college leaders shall give relatively more attention and guidance on this part. "If college leaders value scientific research and know the missions and strategies of it, a strong scientific research environment will be formed among higher vocational colleges" [2]. Following are the detailed four aspects:

Provide support for scientific research - to set up organizations for scientific research affairs management and scientific research project management.

Formulate policies and operation guidelines - such as teacher subsidies and awards on scientific research, overall development plans for teachers, and the establishment and operation of a scientific research committee or an academic board.

Offer financial and laboratory equipment guarantee - to provide the support of acquired policies, detailed scientific research procedures, intellectual property policies, and operation instructions.

Value scientific research affairs - college leaders shall take the lead to actively participate in scientific research, which would set a model for college teachers to follow.

\subsection{Duties of Tier-Two Schools (Faculties) in Scientific Research.}

Lay down scientific and effective management methods for scientific research. "College management shall take the stock of the situation, and scientifically divide the two-tier management model authorities, so as to convert functions and lower the focus of management" [3]. Tier-two schools of higher vocational colleges shall have a clear view of scientific research strategies and goals, and related rules and regulations such as Two-Tier Management Methods of Scientific Research, Two-Tier Evaluation Methods of Scientific Research and Job Responsibilities of Scientific Research Secretary. With the expansion of tier-two schools' autonomous rights related to teaching and scientific research, scientific workload steeply increases. For this reason, tier-two schools shall set up a special management post named scientific research secretary, so as to better provide facilities and management and maintenance services to teachers for the sake of scientific research under the direct leadership of headmasters in charge of scientific research, set aside certain budgets and internal resources for scientific research, and perform quality management and supervision over the process of scientific research. Support shall be given to teachers for scientific research tasks, including peer review, check and approval of scientific research application, hiring exceptional talents, providing good scientific research environment, and the confirmation of fields where scientific research shall be promoted first, specifically speaking, building sound team discussion spaces, subsidization for academic visits and academic conferences, paying scientific research consumables expenses and other expenditures, managing academic accreditations, and funding scientific and cultural events.

Detail and perform scientific research tasks oriented to application for scientific research projects. Tier-two colleges' scientific research work shall be oriented to the application for scientific research projects. Only by detailing scientific research tasks and providing useful guidance on project planning and application form filing can the management work be effectively and thoroughly performed. Following are characteristics of the two commonest types of natural science funds projects, National Natural Science Funds and Provincial Natural Science Funds.

National Natural Science Funds provide a wide range of choices of projects and types with a focus on innovation and open and transparent application evaluation processes. A teacher's previous achievements on related projects, which should accumulate in a focused field, count first in the evaluation process, followed by the teacher's academic influence in related fields. And innovation is even more valued by such funds intended for the youth. Provincial Natural Science Funds attaches importance to characteristics with flexible requirements for projects. It features relatively low 
thresholds and suits young and middle-aged teachers with a master's or doctor's degree who are seeking for initial projects.

\subsection{Make Clear Individuals' Duties in Scientific Research.}

Scientific research project directors must be fully aware of the scientific mind for team working, stress cooperation and inter-discipline complementation, and understand the relationship between interaction, cooperation, and partnership in scientific research; value the development of scientific minds and the incentive of scientific research environment such as seminars, problem discussions, special report meetings, encouragement for academic conferences or visits, and display on websites; behave by management regulations of scientific research quality and the management routines of scientific research projects; exert their role as a leader in the application for scientific research projects and contact with potential sponsors and school or college leaders for as much scientific research support as possible in both financial and policy terms; actively participate in peer reviews and promote the popularization and application of scientific achievements.

\subsection{Reinforce the Duties of Teachers as Individual Researchers in Scientific Research.}

Scientific research capability is a major or even the strongest indicator of faculty strength of a college. Teachers of a college must make a personal development plan and scientific research career strategies in combination with personal specialties and work; foster scientific minds and scientific research capability, get involved in scientific research environment, and make contributions to the construction and development of key disciplines in tier-two schools; value and obey scientific research quality management, and use knowledge in other forms to keep an active and necessary contact with project directors and school leaders; utilize the knowledge of related disciplines to actively promote the popularization and application of scientific achievements, build multi-discipline and multi-level contacts and scientific research partnerships, and eventually to complete a specific scientific research project and apply the achievements to pedagogical practices.

As the main body of teaching organizations and management, tier-two schools should pay attention to arousing enthusiasm and proactivity out from the teachers in scientific research; and should note that the incentive shall be more based on personal development for those who are at the initial stage of scientific research.

\subsection{Duties of Scientific Research Management Departments.}

The management staff of scientific research departments in higher vocational colleges shall reinforce their management awareness of scientific research, bring new ideas to scientific research management and operational system, and create a scientific and well-organized research environment. "It's the foremost task to update the awareness of scientific research management that current colleges are confronted with, and the basis of an innovative system of scientific research is the conversion of views" [5]. Successful scientific research management is of promotional effects in the performance of scientific research and the formation of a well-organized research environment. The following are three common incentive theories in scientific research management:

Herzberg's Two-Factor Theory: this theory states that there're two types of factors affecting working satisfaction, one consists hygiene factors and the other one has "motivators" that are related to work and can really cause positive satisfaction.

Adams' Equity Theory: this theory takes an individual's sense of equity as a kind of subject feeling that forms after a comparison with others and depends on the relative value instead of absolute value of payoffs. People are very sensitive to inequities which may strongly affect satisfaction.

Skinner's Reinforcement Theory: this theory states that all types of praise, awards, and promotion are positive reinforcement and all types of criticism and punishment are negative reinforcement. An incentive system shall take advantage of both.

Simple material reward is just a preliminary and necessary incentive. It's more important to publicize the incentive system in a motivating way on different occasions. Various incentive mechanisms shall be properly integrated to build a scientific and effective incentive system. For instance, Quantitative Evaluation Methods in Scientific Research can only make scientific management staff have a clear understanding and target of the scientific research environment in the 
college by utilizing Management Methods of Recruitment for Scientific Research Posts at Colleges (Schools), Workload Calculating Methods of Teaching and Scientific Research Related Posts, Performance Pay Standards of Teaching and Scientific Research Related Posts, Special Subsidy Policy for Senior Professional Technical Posts And Highly Educated Employees, and finally to enable the teachers involved in scientific research have regulations to abide by, rules to follow, and goals to work for.

\section{Summary}

With the underway improvement of scientific research capabilities at higher vocational colleges and the further advancement of incentive and service management model of scientific research, more complicated situations and challenges will come in the future to scientific management work. Only by continuously seeking for innovations and improving scientific research service levels in scientific research management can science researchers make due contributions to accelerating the development of scientific research and enhancing the scientific research capabilities of colleges.

\section{Acknowledgments}

Fund project: project grant of research project of education department of Shaanxi province (project no.: 17JK0399).

\section{References}

[1]. Department of Higher Education, Ministry of Education of the People's Republic of China. Joint Conference of National Higher Vocational College Headmasters - Upgrade Quality - Guidelines on Pedagogical Practices and Scientific Research Management for Higher Vocational Colleges [M]. Beijing: Higher Education Press, 2005.1.

[2]. Yu, Y.J., A Study of Scientific Research Management at Higher Vocational Colleges [M]. Chengdu: Southwest Jiao tong University Press, 2012: 143, 146.

[3]. Yu, Y.J., A Discussion about Problems and Solutions to Two-Tier Management Model at Higher Vocational Colleges [J]. Journal of Hubei Radio \& Television University, 2010, 30 (1): 32-33.

[4]. Guan, Y.C. \& L. Chen, a Discussion about the Innovation of Scientific Research Management Work at Universities under New Situation [J]. Journal of Sichuan Normal University (Natural Science), 2010, 33 (7): 568-571. 